\title{
Detecção simultânea de fatores de resistência à murcha de fusário do tomateiro por meio de PCR multiplex
}

\author{
Renato Carrer Filho(1), Vanessa Duarte Dias(1), Renata Maria de Oliveira(1), \\ Érico de Campos Dianese ${ }^{(1)}$, Leonardo Silva Boiteux ${ }^{(2)}$ e Marcos Gomes da Cunha ${ }^{(1)}$
}

(1)Universidade Federal de Goiás, Escola de Agronomia, Setor de Fitossanidade, Núcleo de Pesquisa em Fitopatologia, CEP 74690-900
Goiânia, GO, Brasil. E-mail: carrerfilho@hotmail.com, nessaduartedias@hotmail.com, renata_oliveira89@hotmail.com, edianese@ufg.br,
mgcagro@gmail.com (2)Embrapa Hortaliças, Caixa Postal 0218, CEP 70359-970 Brasília, DF, Brasil. E-mail: leonardo.boiteux@embrapa.br

Resumo - O objetivo deste trabalho foi elaborar e validar um protocolo de detecção simultânea, via reação em cadeia da polimerase multiplex (PCR multiplex), de regiões genômicas do tomateiro (Solanum lycopersicum) associadas a fatores de resistência às três raças fisiológicas de Fusarium oxysporum f. sp. lycopersici (FOL). Os pares de iniciadores empregados foram SSR-67 (específico para o gene I-1), TFusrr (específico para o gene I-2) e SSRD (específico para o gene I-3). Os resultados de genotipagem com marcadores moleculares foram comparados aos resultados de fenotipagem de uma coleção de germoplasma de tomateiro, em bioensaios de inoculação de isolados das três raças de FOL em plântulas, pelo método de imersão das raízes. A resistência ou a suscetibilidade foi confirmada por PCR, por meio de visualização dos âmplicons específicos para as regiões-alvo ligadas aos fatores de resistência às distintas raças de FOL. O protocolo elaborado para o uso conjunto dos marcadores moleculares, em PCR multiplex, permite a seleção de acessos de tomateiro resistentes às raças 1,2 , e 3 de $F$. oxysporum f. sp. lycopersici de maneira similar à realizada com a utilização de cada um separadamente. O PCR multiplex representa uma ferramenta viável para monitorar a incorporação desses fatores de resistência em linhagens de tomateiro.

Termos para indexação: Fusarium oxysporum, Solanum lycopersicum, resistência genética, seleção assistida.

\section{Simultaneous detection of tomato resistance factors to Fusarium wilt in tomato by multiplex PCR}

\begin{abstract}
The objective of this work was to develop and validate a protocol for simultaneous detection by multiplex polymerase chain reaction (multiplex PCR) of tomato (Solanum lycopersicum) genomic regions associated with factors of resistance to three physiological races of Fusarium oxysporum $\mathrm{f}$. sp. lycopersici (FOL). The employed primer pairs were SSR-67 (specific to the $I-1$ gene), TFusrr (specific to the $I-2$ gene), and SSRD (specific to the $I-3$ gene). Genotyping results with molecular markers were compared with the phenotyping ones of a tomato germplasm collection, in bioassays of isolate inoculation of the three FOL races in seedlings by root dipping. The resistance or susceptibility was confirmed by PCR, through the visualization of specific amplicons corresponding to the target regions linked to the factors of resistance to distinct FOL races. The elaborated protocol for the joint use of the molecular markers, by multiplex PCR, allows of the selection of tomato accessions that are resistant to the races 1,2 , and 3 of $F$. oxysporum $\mathrm{f}$. sp. lycopersici in a similar way to that done with each one separately. PCR multiplex is a viable tool to monitor the incorporation of these resistance factors into tomato inbred lines.
\end{abstract}

Index terms: Fusarium oxysporum, Solanum lycopersicum, genetic resistance, assisted breeding.

\section{Introdução}

A murcha de fusário do tomateiro (Solanum lycopersicum L.) é causada pelo fungo Fusarium oxysporum f. sp. lycopersici (FOL), que apresenta três raças fisiológicas e é um dos principais problemas fitossanitários da cultura no Brasil (Reis et al., 2005; Reis \& Boiteux, 2007; Gonzalez-Cendales et al.,
2016). FOL apresenta estruturas de resistência que asseguram sua sobrevivência em condições ambientais adversas, o que garante assim sua viabilidade em áreas de cultivo (Carrer Filho et al., 2015a). As raças fisiológicas de FOL em tomateiro são caracterizadas de acordo com a capacidade de infectar e causar doença a acessos diferenciadores que carregam distintos genes e loci de resistência. Em tomateiro, quatro genes de 
resistência da denominada série I (Immunity) conferem resistência específica à raça de isolados de FOL (Ma et al., 2013). Estes genes, designados como $I-1, I-2, I-3$ e $I-7$ foram caracterizados em espécies selvagens de Solanum (Lycopersicon) e introgredidos em cultivares comerciais de tomateiro (Huang \& Lindhout, 1997; Houterman et al., 2008).

A introgressão dos genes $I-1$ (resistência à raça 1) e I-2 (resistência à raça 2) se tornou o principal método preventivo da doença (Đorđević et al., 2012). Isto se deve, principalmente, à extrema eficiência destes genes de defesa do hospedeiro contra essas duas raças, que apresentam uma distribuição geográfica mais ampla (Carrer Filho et al., 2015a). Os genes I-3 e I-7 (introgredidos de diferentes acessos da espécie silvestre $S$. pennellii) estão localizados em distintos cromossomos e controlam a resistência a isolados de FOL raça 3 (Gonzalez-Cendales et al., 2016). Em razão da recente introdução de isolados da raça 3 no Brasil, os fatores de resistência $I-3$ e $I-7$ ainda não estão disponíveis em grande escala, em variedades adaptadas para as regiões tropicais e subtropicais do país (Barboza et al., 2013). Fontes de resistência a isolados de FOL raça 3 têm sido também identificadas em acessos de S. pimpinellifolium, S. corneliomulleri, S. parviflorum, S. habrochaites, S. chilense e S. peruvianum (Huang \& Lindhout, 1997; Reis et al., 2004; Carrer Filho et al., 2015b); no entanto, os fatores genéticos associados à resistência a FOL raça 3 , nesses acessos, ainda não foram caracterizados nem mapeados em tomateiro.

Um processo mais eficiente de "piramidização" de todos os genes da série $I$, em germoplasma-elite de tomateiro, requer a combinação de análises por meio de bioensaios e o auxílio de seleção assistida por marcadores moleculares, ligados aos principais genes de resistência efetivos contra todas as variantes de FOL. Marcadores moleculares ainda não estão disponíveis para o gene $I-7$, que foi apenas recentemente clonado (Gonzalez-Cendales et al., 2016). No entanto, sistemas de marcadores moleculares específicos foram desenvolvidos e já se encontram disponíveis para monitorar as regiões genômicas que contêm os fatores de resistência I-1 (Parmar \& Subramanian, 2011), I-2 (El Mohtar et al., 2007) e I-3 (Scott et al., 2004; Lim et al., 2008). Esses sistemas têm sido empregados para auxiliar o processo de seleção assistida, mas a metodologia limita-se, até o presente momento, pela caracterização isolada de cada gene-alvo (Carrer Filho et al., 2015b).

Neste contexto, é necessário o estabelecimento de uma metodologia rápida e eficiente de detecção simultânea de múltiplos genes-alvo, envolvidos no controle da resistência às diferentes raças fisiológicas do patógeno, tanto para trabalhos de pesquisa relacionados ao patossistema como para programas de melhoramento, que utilizam esta ferramenta auxiliar na seleção assistida.

O objetivo deste trabalho foi elaborar e validar um protocolo de detecção simultânea, via reação em cadeia da polimerase multiplex (PCR multiplex), de regiões genômicas do tomateiro associadas a fatores de resistência às três raças fisiológicas de Fusarium oxysporum f. sp. lycopersici (FOL).

\section{Material e Métodos}

Os bioensaios com os acessos de tomateiro foram realizados em casa de vegetação, à temperatura média de $30 \pm 7^{\circ} \mathrm{C}$ e umidade relativa do ar de 40 a $70 \%$. Foram utilizados três isolados do patógeno, denominados de FOL-27 (raça 1), FOL-1114 (raça 2) e FOL-2124 (raça 3), que foram obtidos de plantas sintomáticas de tomateiro, coletadas em Brasília, DF, Comacim de São Félix, PE, e Domingos Martins, ES, caracterizados e cedidos pelo Centro Nacional de Pesquisa em Hortaliças (CNPH), pela Universidade Federal Rural de Pernambuco (UFRPE), e pelo Instituto Capixaba de Pesquisa, Assistência Técnica e Extensão Rural (Incaper), respectivamente. A coleção de acessos de tomateiro foi formada por nove cultivares ('Roma VF1', 'IPA 6', 'Rio Grande 1', 'Rossol', 'Macero', 'Fineto 2', 'IPA 7', 'Rio Grande 2' e 'Santa Clara'), três híbridos ('BRS Sena', 'IT 761' e 'CVR 2909'), três acessos selvagens de Solanum (S. corneliomulleri 'LA-1113-1', $S$. peruvianum 'LA-1677' e $S$. pimpinellifolium 'CNPH-1678'), oriundos do banco de germoplasma da Embrapa Hortaliças. Seis linhagens $\mathrm{F}_{12}$ (PX-201, PX-202, PX-203, PX-204, PX-205 e PX-206), provenientes do programa de melhoramento da Vivati Plant Breeding Ltda., Rio Verde, GO, também foram avaliadas. Os controles positivos foram as cultivares diferenciadoras de raças: 'Ponderosa' (suscetível às raças 1, 2 e 3) (Reis et al., 2004); 'Viradoro' (resistente à raça 1 e suscetível às raças 2 e 3) (Giordano et al., 2000) e 'Floradade' (resistente às raças 1 e 2 e suscetível 
à raça 3) (Reis et al., 2004). Foram também incluídos os acessos S. pennellii 'LA-716' (Scott \& Jones, 1989), S. corneliomulleri 'LA-1113-1', S. peruvianum 'LA-1677' e S. pimpinellifolium 'CNPH-1678', que foram previamente identificados como resistentes a todas as três raças de FOL (Carrer Filho et al., 2015b).

O preparo do inóculo dos isolados foi feito com três discos de micélio de cada cultura, com $5 \mathrm{~mm}$ de diâmetro, em meio batata-dextrose-ágar (BDA), depositados em frascos de Erlenmeyer, que continham $250 \mathrm{~mL}$ de meio de cultura batata-dextrose (BD) autoclavado. Após 15 dias de crescimento em agitador automático (120 rpm), à temperatura de $25^{\circ} \mathrm{C}$ e com iluminação fluorescente contínua, as suspensões de cada inóculo foram homogeneizadas e filtradas, e a concentração foi ajustada a $1 \times 10^{6}$ de microconídios $\mathrm{mL}^{-1}$, com auxílio da câmara de Neubauer. A inoculação dos isolados de FOL foi realizada pelo método do corte de raízes e imersão na suspensão de esporos (Reis et al., 2004). Por esta metodologia, as plântulas de tomateiro com 15 dias após a emergência, cultivadas em substrato Plantmax, em condições de casa de vegetação, foram removidas das bandejas de poliestireno e submetidas à lavagem da raiz, para a retirada do substrato e o corte da região apical, a cerca de $2 \mathrm{~cm}$ acima da extremidade das raízes. Em seguida, foram imersas por $3 \mathrm{~min}$ na suspensão de conídios, até a altura da região do colo, e transplantadas para vasos de polipropileno $(1,0 \mathrm{~L})$ que continham solo areno-argiloso autoclavado. A testemunha consistiu de plantas com raízes cortadas e imersas em solução sem a presença de conídios do patógeno.

A severidade da doença foi avaliada aos 23 dias após a inoculação, por meio de uma escala de notas de 1 a 5 , em que: 1, planta sem sintomas; 2 , planta sem sintoma de murcha, mas com suave descoloração vascular; 3, planta com sintomas de murcha e descoloração vascular; 4, planta com severa murcha associada à presença de clorose e necrose foliar; e 5, planta morta (Reis et al., 2004). A média de severidade da doença foi calculada em cada genótipo. Em seguida, os genótipos foram arbitrariamente agrupados nas seguintes cinco classes de reação: 1,0, do tipo imunidade (SI); 1,1-2,0, altamente resistente (AR); 2,1-3,0, medianamente resistente (MR); 3,1-4,0, suscetível (SU); e 4,1-5,0, altamente suscetível (AS). Quatro repetições foram feitas por isolado, e cada repetição foi constituída por um vaso, com três plantas cada, utilizando-se o delineamento experimental inteiramente casualizado. Os dados foram submetidos à análise de variância, pelo programa estatístico Sisvar (Universidade Federal de Lavras, Lavras-MG, Brasil).

Para a extração de DNA genômico do tomateiro, coletaram-se 0,2 g de tecido (aos 20 dias após emergência), que foi purificado por meio do método CTAB 2X, com algumas modificações (Boiteux et al., 1999). As purificações de DNA foram quantificadas em espectrofotômetro. Em todos os ensaios de PCR, utilizaram-se 4,5 $\mu \mathrm{L}$ de Premix 2X (EmeraldAmp GT PCR Master Mix, Takara Bio Inc, Otsu, Shiga, Japão), $1,0 \mu \mathrm{L}$ DNA a $80 \mathrm{ng} \mu \mathrm{L}^{-1}, 0,2 \mu \mathrm{L}$ de cada iniciador ajustado a 2,5 pM e água Milli-Q para completar o volume final de $11,0 \mu \mathrm{L}$.

Para detectar a presença da região genômica que contém o gene $I-1$, empregou-se o par de iniciadores SSR-67 FP (5'-GCA-CGA-GAC-CAA-GCA-GA T-TA-3') e SSR-67 RP (5'-GGG-CCT-TTC-CTC -CAG-TAG-AC-3'), que amplificam uma região de aproximadamente $900 \mathrm{pb}$ (Parmar et al., 2009). Para monitorar o gene $I$-2, utilizou-se um sistema de marcadores funcionais com os iniciadores TFusrr1 RP (5'CGA-AGA-GTG-ATT-GGA-GAT-3'), TFusrr2 RP (5'-CCT-GGA-TGA-ACA-GCT-GAG-3') e TFusF1 FP (5'-CTG-AAA-CTC-TCC-GTA-TTT-C-3'), que produzem um âmplicon polimórfico de cerca de $600 \mathrm{pb}$ (El Mohtar et al., 2007). Finalmente, para monitorar o gene $I-3$, utilizou-se um marcador microssatélite gerado pelos iniciadores SSRD-F1 (5'-ATT-GAA-GTG-ATCTTG-TTT-ATG-AAT-C-3') e SSRD-R1 (5'-GAC-A AA-TTA-GCT-AAG-AGT-AGC-TTC-AC-3') (Lim et al., 2008). As plantas homozigotas para o gene $I-3$ apresentam apenas um âmplicon de $350 \mathrm{pb}$, e as plantas homozigotas para o alelo de suscetibilidade apresentam apenas um âmplicon de $300 \mathrm{pb}$. Os iniciadores foram empregados separada ou simultaneamente e em todas as possíveis combinações duplas. $\mathrm{O}$ protocolo do ensaio de PCR envolveu uma etapa inicial de desnaturação $\left(95^{\circ} \mathrm{C}\right.$ por $\left.1 \mathrm{~min}\right)$, seguida por 35 ciclos de desnaturação a $95^{\circ} \mathrm{C}$ por $30 \mathrm{~s}$, anelamento a $54^{\circ} \mathrm{C}$ por $45 \mathrm{~s}$ e $72^{\circ} \mathrm{C}$ por $45 \mathrm{~s}$, para extensão, e $72^{\circ} \mathrm{C}$ por $5 \mathrm{~min}$ de extensão final. Os ensaios de PCR foram realizados em termociclador Biocycler (Biosystem, Curitiba, PR, Brasil). Todos os produtos de PCR foram separados em gel de agarose a 1,5\%, pré-fundido em GelRed com tampão TBE a $80 \mathrm{~V}$, e visualizados em transiluminador UV.

Pesq. agropec. bras., Brasília, v.51, n.8, p.925-932, ago. 2016 DOI: 10.1590/S0100-204X2016000800004 


\section{Resultados e Discussão}

Nos bioensaios, todas as variedades e híbridos de tomateiro confirmaram a reação de resistência ou suscetibilidade, em confronto com os isolados FOL-27 (raça 1), FOL-1114 (raça 2) e FOL-2124 (raça 3), o que corrobora seus fenótipos com as reações previamente conhecidas (Figura 1).

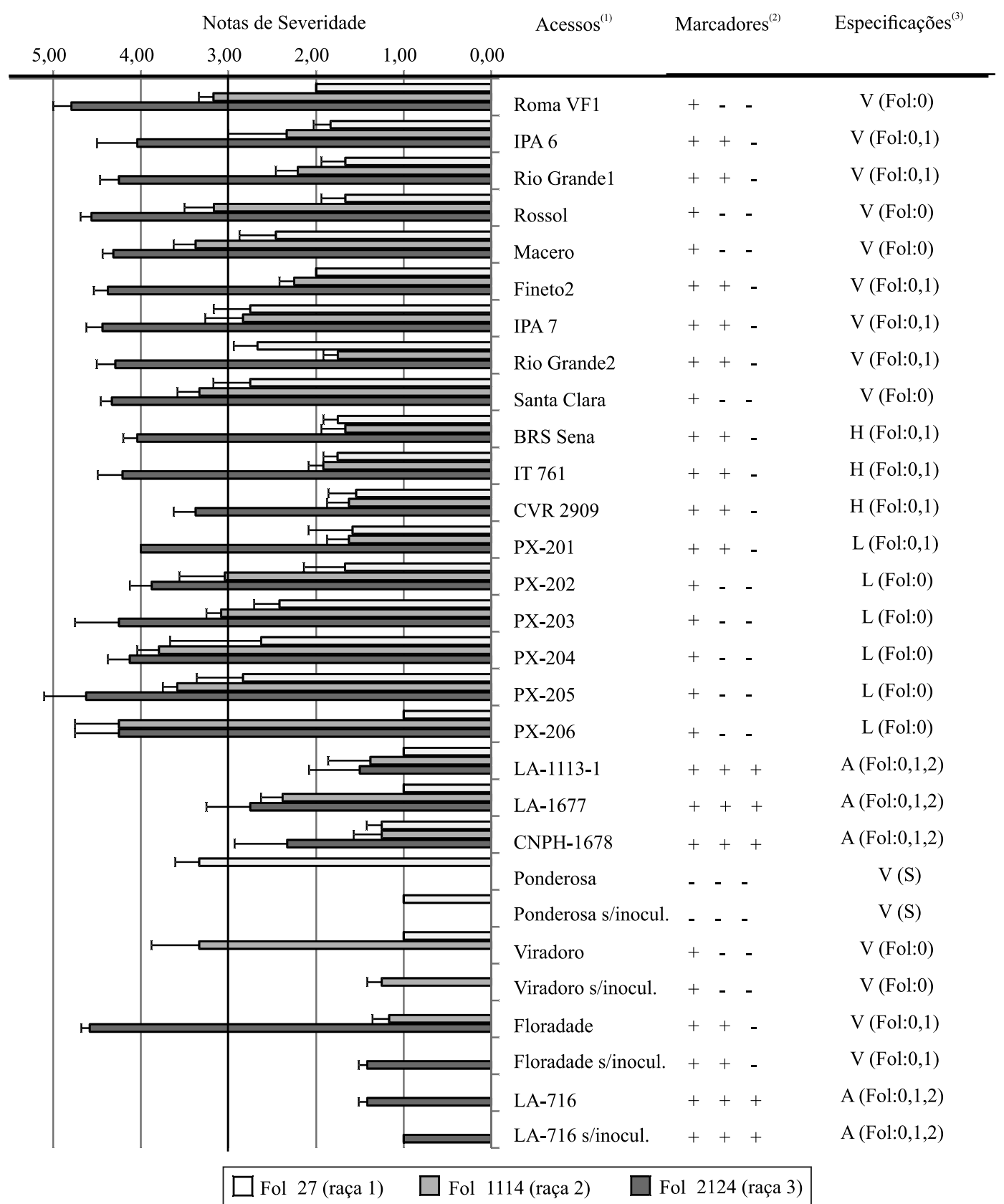

Figura 1. Reação fenotípica de acessos de tomateiro à murcha de fusário, avaliados aos 23 dias após inoculação do patógeno. ${ }^{(1)}$ Representação das médias das notas, agrupadas por classe de reação ao patógeno, em que: 1,0, reação semelhante à imune; 1,1-2,0, altamente resistente; 2,1-3,0, medianamente resistente; 3,1-4,0, suscetível; e 4,1-5,0, altamente suscetível. ${ }^{(2)}$ Caracterização molecular com os iniciadores SSR-67, TFussr e SSRD-1, utilizados para a detecção dos genes $I-1, I-2$ e $I$-3, que expressam resistência às raças 1, 2 e 3 do patógeno, respectivamente. ${ }^{(3)}$ Caracterização dos acessos, em que: V, variedade; H, híbrido; L, linhagem; A, acesso silvestre; e caracterização da resistência a Fusarium oxysporum f. sp. lycopersici (Fol:0, raça 1 ; Fol:0,1, raça 2; Fol:0,1,2, raça 3; S, susceptível a todas as raças). 
Todas as linhagens apresentaram reação de resistência, quando infectadas com a raça 1 do patógeno, que variaram de reação do tipo imune, moderadamente resistente e altamente resistente (Figura 1). Apenas a linhagem PX-201 apresentou reação de resistência à raça 2 , o que confirma a introgressão simultânea dos genes $I-1$ e $I-2$, oriundos de progenitores masculino (PM-Fol:0,1) e feminino (PF-Fol:0,1), caracterizados como portadores de fatores de resistência às raças 1 e 2 do fitopatógeno. Os bioensaios com as raças 1 e 2 mostraram razoável frequência de acessos com reação intermediária (MR). Esse tipo de resposta para FOL raça 1 e FOL raça 2 tem sido relatado em outros trabalhos, o que indica a existência de fonte de resistência parcial ou incompleta para essas variantes do patógeno (Đorđević et al., 2012; Carrer Filho et al., 2015b), como também a possibilidade de influência de alguns fatores, tais como dano severo às raízes, durante a inoculação, e a influência do ambiente (Reis et al., 2004). Possíveis instabilidades de expressão dessa natureza são oriundas, principalmente, de combinações de genótipos hospedeiros, variabilidade patogênica e ambiental (Amini, 2009; Đorđević et al., 2012). Essa instabilidade fenotípica não é desejável dentro de programas de melhoramento, em razão de potenciais "quebras de resistência" de fontes portadoras desses genes.

Os acessos de tomateiro mostraram reação do tipo suscetível (S) à altamente susceptível (AS) quando infectados com o isolado Fol-2124 (raça 3) (Figura 1). Estes resultados ratificam a ausência do gene $I-3$, que expressa resistência à raça 3 do patógeno, neste germoplasma. Somente os acessos selvagens provenientes do banco de germoplasma da Embrapa Hortaliças (CNPH), utilizados como acessos diferenciadores, expressaram reação de resistência às três raças fisiológicas do fitopatógeno.

Os resultados do bioensaio, provenientes das inoculações dos isolados de cada raça do patógeno, foram confirmados pelos resultados moleculares advindos da técnica de PCR convencional, com o uso individual dos marcadores específicos para as regiões genômicas que contêm os fatores de resistência $I-1$ (SSR-67), I-2 (TFusrr) e I-3 (SSRD1) (Figura 2). Quando os três pares de iniciadores foram utilizados simultaneamente, eles sempre amplificaram as regiões específicas do DNA correspondentes aos genes-alvo associados à expressão da resistência às raças

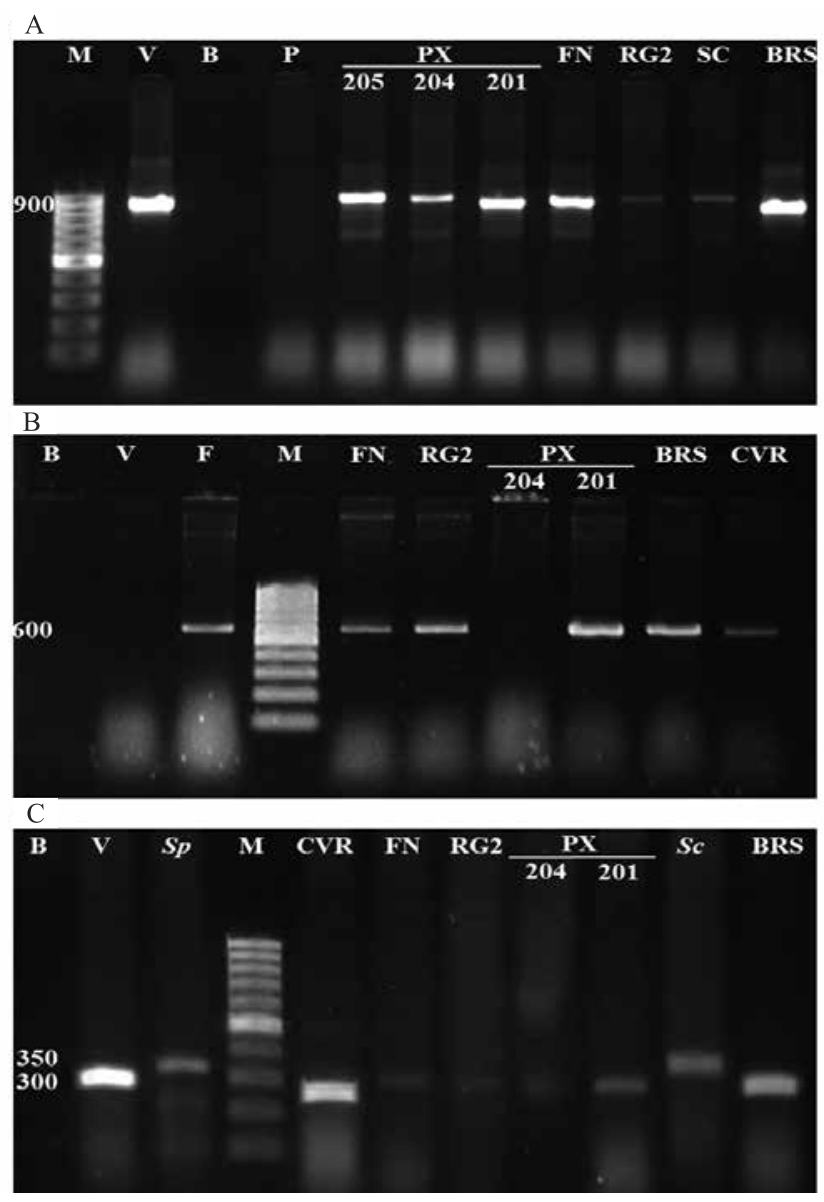

Figura 2. Perfil polimórfico da amplificação da PCR - em gel de agarose a $1,5 \%$, em solução de TBE -, obtido com o uso dos iniciadores SSR-67 (A), TFusrr (B) e SSRD-1 (C). Os ensaios de PCR foram realizados com DNA genômico extraído de acessos de tomateiro. $\mathrm{A}$, acessos resistentes à raça 1 de FOL, como a cultivar 'Viradoro' (V), e tolerante, como a 'Santa Clara' (SC), mostram alelos de 900 pb, em comparação à cultivar suscetível, sem amplificação, caracterizada pela 'Ponderosa' (P). O gel ilustra o padrão de âmplicons do híbrido 'BRS Sena' (BRS), das cultivares 'Fineto 2' (FN) e 'Rio Grande 2' (RG2) e das linhagens PX-201, PX-204 e PX-205. B, acessos resistentes à raça 2 de FOL, como a cultivar 'Floradade' (F), mostram alelos de 600 pb, em comparação à variedade suscetível, sem amplificação, caracterizada pela 'Viradoro' (V). As cultivares, as linhagens e o híbrido são os mesmos descritos no painel A, além do híbrido 'CVR 2909' (CVR). C, acessos resistentes à raça 3 de FOL, como Solanum pennellii $(S p=$ 'LA-716') e $S$. corneliomulleri ( $S c=$ 'LA 1113-1') mostram alelos de 350 pb, em comparação à cultivar suscetível, com amplificação de $300 \mathrm{pb}$, caracterizada pela 'Viradoro' (V). Os híbridos, linhagens e variedades são os mesmos descritos nos painéis A e B. Marcador (M) ladder $100 \mathrm{pb}$ e controle negativo com água (B). 
fisiológicas do patógeno. Não se observaram, portanto, âmplicons extras que pudessem dificultar a análise dos géis. Quando utilizados concomitantemente dois pares de iniciadores, em todas as combinações possíveis, fragmentos esperados também foram observados, o que representa a detecção das respectivas regiões-alvo (Figura 3). Um interessante resultado com os marcadores TFusrr e SSRD1, quando usados

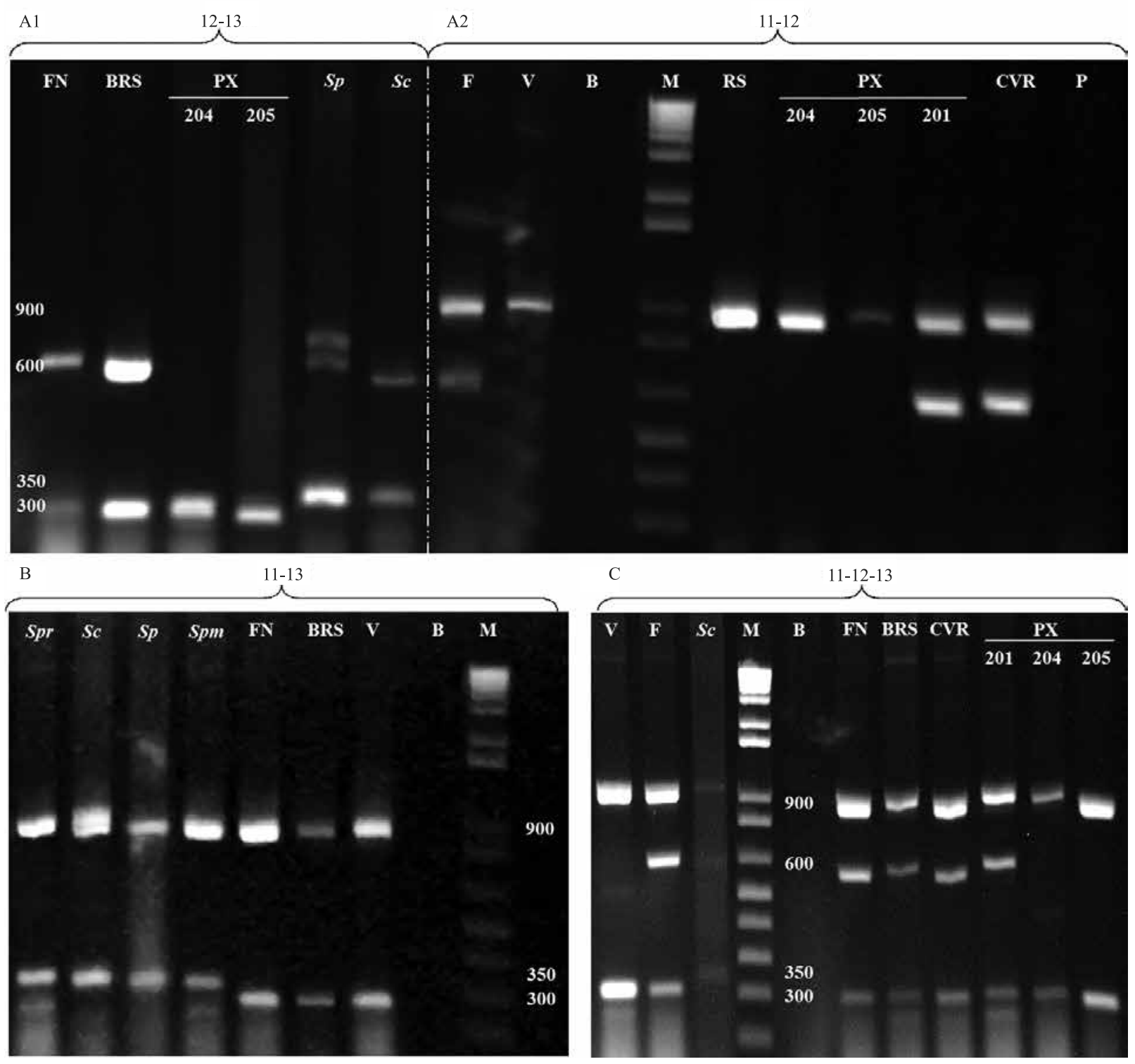

Figura 3. Perfil polimórfico da amplificação da PCR multiplex - em gel de agarose a 1,5\% em solução de TBE -, obtido com o uso dos iniciadores SSR-67, TFusrr e SSRD-1, em combinações duplas (painéis A1, A2 e B) ou simultaneamente (painel C). Os ensaios de PCR foram realizados com DNA genômico extraído de acessos de tomateiro. Acessos resistentes à raça 1 de FOL, como a cultivar 'Viradoro' (V) e os materiais genéticos 'BRS Sena' (BRS), 'CVR 2909' (CVR), 'Fineto 2' (FN), 'Rossol' (RS), as linhagens PX-201, PX-204 e PX-205 e os acessos silvestres S. pennellii (Sp), S. corneliomulleri (Sc), S. peruvianum (Spr) e S. pimpinellifolium (Spm) mostram alelos de $900 \mathrm{pb}$, em comparação à cultivar suscetível 'Ponderosa' (P), sem produto de amplificação. Genótipos resistentes à raça 2 de FOL, como 'Floradade' (F), 'BRS Sena' (BRS), 'CVR 2909' (CVR), 'Fineto 2' (FN), PX-201 e $S p$, mostram alelos de 600 pb, em comparação à cultivar suscetível 'Viradoro' (V), sem amplificação. Acessos resistentes à raça 3 de FOL, como S. pennellii $(S p=$ 'LA-716'), S. corneliomulleri ( $S c=$ 'LA 1113-1'), S. peruvianum $(S p r=$ 'LA 1677') e S. pimpinellifolium (Spm = 'CNPH-1678') mostram alelos de $350 \mathrm{pb}$, em comparação à cultivar suscetível, com amplificação de 300 pb, caracterizada por 'Viradoro' (V) e 'Floradade' (F). Marcador 1 pb (M) e controle negativo com água (B). 
simultaneamente, é um polimorfismo de posição no material resistente $S$. pennellii, que indica a presença de um âmplicon inespecífico mais lento em gel, próximo ao fragmento esperado (Figura $3 \mathrm{~A} 1$ ). Em todas as situações, a PCR multiplex, que continha a mistura de pares de iniciadores, foi capaz de identificar a região especifica associada à expressão da resistência, aparentemente sem nenhuma competição ou inibição entre os iniciadores.

A detecção de resistência a diversas doenças do tomateiro via PCR tem sido empregada em sistemas de seleção assistida ou em estudos em diferentes patossistemas do tomateiro (El Mohtar et al., 2007; Arens et al., 2010; Dianese et al., 2010). Marcadores específicos têm sido usados com sucesso, para detecção de resistência à murcha do tomateiro causada por Fusarium (Lim et al., 2006; El Mohtar et al., 2007; Staniaszek et al., 2007; Amini, 2009; Parmar et al., 2009). No entanto, protocolos de PCR multiplex ainda não foram desenvolvidos, o que permite apenas o monitoramento de um fator de resistência por reação.

A otimização da técnica de PCR multiplex, para a detecção e identificação de mais de uma região associada à resistência a FOL, em acessos de tomateiro, foi possível graças à especificidade que cada marcador apresenta com o gene/locus correspondente. A combinação desse conjunto de iniciadores resultou na produção de âmplicons (bandas inespecíficas) de tamanhos bem distintos, sem que houvesse uma sobreposição dos âmplicons nos géis, o que facilita a interpretação dos resultados, ou seja, não apresentaram inibição nem competição. Todas essas características, aliadas às temperaturas de anelamento similares observadas nos três sistemas de marcadores, permitiram o emprego simultâneo desse conjunto de iniciadores em protocolos de PCR multiplex.

Considerando-se a rapidez e a viabilidade, o método de PCR multiplex, elaborado e validado no presente trabalho, pode funcionar como uma importante ferramenta para auxiliar e otimizar a seleção assistida de fatores de resistência a FOL, em programas de melhoramento. Além da vantagem de reduzir o custo e o tempo de análise, torna mais dinâmico o processo de avaliação de rotina, principalmente quando aplicado em larga escala, tanto em comparação ao método convencional de PCR quanto em avaliações fenotípicas, e pode usar diferentes formatos, como duplex ou triplex PCR. O procedimento adotado é o primeiro a mostrar a detecção simultânea, por meio de
PCR multiplex, de fatores de resistência às três raças fisiológicas de FOL. Marcadores moleculares ainda não estão disponíveis para o gene $I-7$, que foi apenas recentemente clonado (Gonzalez-Cendales et al., 2016). Assim, ajustes metodológicos serão necessários para uma potencial inclusão de marcadores ligados ao locus $I-7$, no sistema de PCR multiplex descrito no presente trabalho.

\section{Conclusão}

O uso conjunto dos marcadores moleculares SSR-67, TFusrr e SSRD1, por meio de PCR multiplex, permite a seleção simultânea de acessos de tomateiro resistentes às raças 1,2 e 3 de $F$. oxysporum f. sp. lycopersici, de maneira similar àquela realizada com a utilização de cada um separadamente.

\section{Agradecimentos}

À Coordenação de Aperfeiçoamento de Pessoal de Nível Superior (Capes), pela concessão de bolsa; ao Pesquisador Ailton Reis, Embrapa Hortaliças, Brasília, DF, ao Professor Sami J. Michereff, da Universidade Federal Rural de Pernambuco, Recife, PE, e ao Instituto Capixaba de Pesquisa, Assistência Técnica e Extensão Rural (Incaper), pela disponibilização dos isolados.

\section{Referências}

AMINI, J. Developing of DNA-marker to the Fusarium oxysporum f. sp. lycopersici resistance genes of tomato. Journal of Plant Protection Research, v.49, p.175-178, 2009. DOI: 10.2478/ v10045-009-0025-1

ARENS, P.; MANSILLA, C.; DEINUM, D.; CAVELLINI, L.; MORETTI, A.; ROLLAND, S.; SCHOOT, H. van der; CALVACHE, D.; PONZ, F.; COLLONNIER, C.; MATHIS, R.; SMILDE, D.; CARANTA, C.; VOSMAN, B. Development and evaluation of robust molecular markers linked to disease resistance in tomato for distinctness, uniformity and stability testing. Theoretical and Applied Genetics, v.120, p.655-664, 2010. DOI: 10.1007/s00122-009-1183-2.

BARBOZA, E.A.; CABRAL, C.S.; GONÇALVES, A.M.; REIS, A.; FONSECA, M.E.N.; BOITEUX, L.S. Identification of Fusarium oxysporum f. sp. lycopersici race 3 infecting tomatoes in Northeast Brazil. Plant Disease, v.97, p.422-423, 2013. DOI: 10.1094/PDIS-08-12-0779-PDN.

BOITEUX, L.S.; FONSECA, M.E.N.; SIMON, P.W. Effects of plant tissue and DNA purification method on randomly amplified polymorphic DNA-based genetic fingerprinting analysis in carrot. Journal of the American Society for Horticultural Science, v.124, p.32-38, 1999. 
CARRER FILHO, R.; DIANESE, E. de C.; CUNHA, M.G. da. Aspectos moleculares da interação Fusarium oxysporum f. sp. lycopersici e o tomateiro. Revisão Anual de Patologia de Plantas, v.23, p.110-127, 2015a.

CARRER FILHO, R.; OLIVEIRA, R.M.; DIAS, V.D.; BOITEUX, L.S.; DIANESE, E. de C.; CUNHA, M.G. da. Fontes de resistência múltipla à murcha de fusário em tomateiro. Pesquisa Agropecuária Brasileira, v.50, p.1225-1231, 2015b. DOI: 10.1590/S0100-204X2015001200013.

DIANESE, E.C.; FONSECA, M.E.N. de; GOLDBACH, R.; KORMELINK, R.; INOUE-NAGATA, A.K.; RESENDE, R.O.; BOITEUX, L.S. Development of a locus-specific, co-dominant SCAR marker for assisted-selection of the $S w-5$ (Tospovirus resistance) gene cluster in a wide range of tomato accessions. Molecular Breeding, v.25, p.133-142, 2010. DOI: 10.1007/ s11032-009-9313-8.

ĐORĐEVIĆ, M.; VATCHEV, T.; GIREK, Z.; SEVIĆ, M.; ZEĆEVIĆ, B.; ZDRAVKOVIĆ, J.; IVANOVIĆ, M. Reaction of different tomato cultivars toward race 1 of Fusarium oxysporum f. sp. lycopersici. Genetika, v.44, p.109-118, 2012. DOI: 10.2298/ GENSR1201109D.

EL MOHTAR, C.A.; ATAMIAN, H.S.; DAGHER, R.B.; ABOU-JAWDAH, Y.; SALUS, M.S.; MAXWELL, D.P. Marker-assisted selection of tomato genotypes with the $I$ - 2 gene for resistance to Fusarium oxysporum f. sp. lycopersici race 2. Plant Disease, v.91, p.758-762, 2007. DOI: 10.1094/ PDIS-91-6-0758

GIORDANO, L. de B.; ÁVILA, A.C. de; CHARCHAR, J.M.; BOITEUX, L.S.; FERRAZ, E. 'Viradoro': A Tospovirus-resistant processing tomato cultivar adapted to tropical environments. HortScience, v.35, p.1368-1370, 2000.

GONZALEZ-CENDALES, Y.; CATANZARITI, A.-M.; BAKER, B.; MCGRATH, D.J.; JONES, D.A. Identification of I-7 expands the repertoire of genes for resistance to Fusarium wilt in tomato to three resistance gene classes. Molecular Plant Pathology, v.17, p.448-463, 2016. DOI: 10.1111/mpp.12294.

HOUTERMAN, P.M.; CORNELISSEN, B.J.C.; REP, M. Suppression of plant resistance gene-based immunity by a fungal effector. Plos Pathogens, v.4, p.e1000061, 2008. DOI: 10.1371/ journal.ppat.1000061.

HUANG, C.-C.; LINDHOUT, P. Screening for resistance in wild Lycopersicon species to Fusarium oxysporum f. sp. lycopersici race 1 and race 2. Euphytica, v.93, p.145-153, 1997. DOI: 10.1023/A:1002943805229.

LIM, G.T.T.; WANG, G.-P.; HEMMING, M.N.; BASUKI, S.; MCGRATH, D.J.; CARROLL, B.J.; JONES, D.A. Mapping the I-3 gene for resistance to Fusarium wilt in tomato: application of an $I-3$ marker in tomato improvement and progress towards the cloning of $I-3$. Australasian Plant Pathology, v.35, p.671-680, 2006. DOI: 10.1071/AP06073.

LIM, G.T.T.; WANG, G.-P.; HEMMING, M.N.; MCGRATH, D.J.; JONES, D.A. High resolution genetic and physical mapping of the $I-3$ region of tomato chromosome 7 reveals almost continuous microsynteny with grape chromosome 12 but interspersed microsynteny with duplications on Arabidopsis chromosomes 1, 2 and 3. Theoretical and Applied Genetics, v.118, p.57-75, 2008. DOI: $10.1007 / \mathrm{s} 00122-008-0876-2$.

MA, L.-J.; GEISER, D.M.; PROCTOR, R.H.; ROONEY, A.P.; O'DONNELL, K.; TRAIL, F.; GARDINER, D.M.; MANNERS, J.M.; KAZAN, K. Fusarium Pathogenomics. Annual Review Microbiology, v.67, p.399-416, 2013. DOI: 10.1146/ annurev-micro-092412-155650.

PARMAR, P.; SUBRAMANIAN, R.B. PCR based method for testing Fusarium wilt resistance of tomato. African Journal of Basic and Applied Sciences, v.3, p.219-222, 2011.

PARMAR, P.P.; BHATT, K.N.; OZA, V.P.; PATEL, A.D.; KATHIRIA, K.B.; SUBRAMANIAN, R.B. Microsatellite marker associated with Fusarium wilt resistance in tomato. World Journal of Agricultural Sciences, v.5, p.389-393, 2009.

REIS, A.; BOITEUX, L.S. Outbreak of Fusarium oxysporum f. sp. lycopersici race 3 in commercial fresh-market tomato fields in Rio de Janeiro state, Brazil. Horticultura Brasileira, v.25, p.451-454, 2007. DOI: 10.1590/S0102-05362007000300025.

REIS, A.; COSTA, H.; BOITEUX, L.S.; LOPES, C.A. First report of Fusarium oxysporum f. sp. lycopersici race 3 on tomato in Brazil. Fitopatologia Brasileira, v.30, p.426-428, 2005. DOI: 10.1590/S0100-41582005000400017.

REIS, A.; GIORDANO, L. de B.; LOPES, C.A.; BOITEUX, L.S. Novel sources of multiple resistance to three races of Fusarium oxysporum f. sp. lycopersici in Lycopersicon germplasm. Crop Breeding and Applied Biotechnology, v.4, p.495-502, 2004. DOI: 10.12702/1984-7033.v04n04a19.

SCOTT, J.W.; AGRAMA, H.A.; JONES, J.P. RFLP-based analysis of recombination among resistance genes to Fusarium wilt races 1, 2, and 3 in tomato. Journal of the American Society for Horticultural Science, v.129, p.394-400, 2004.

SCOTT, J.W.; JONES, J.P. Monogenic resistance in tomato to Fusarium oxysporum f. sp. lycopersici race 3. Euphytica, v.40, p.49-53, 1989.

STANIASZEK, M.; KOZIK, E.U.; MARCZEWSKI, W. A CAPS marker $\mathrm{TAO}_{902}$ diagnostic for the $I-2$ gene conferring resistance to Fusarium oxysporum f. sp. lycopersici race 2 in tomato. Plant Breeding, v.126, p.331-333, 2007. DOI: 10.1111/j.1439-0523.200 7.01355.x.

Recebido em 10 de março de 2016 e aprovado em 2 de junho de 2016 